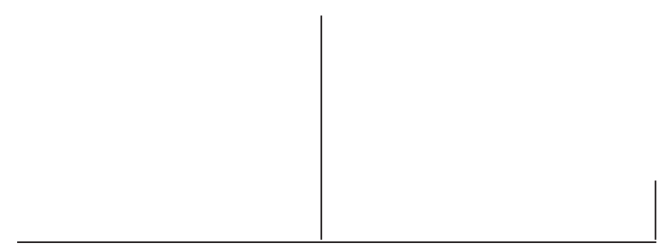

Rev. Latinoam. Psicopat. Fund., IV, 3, 67-88

\title{
Delírio, fantasia e devaneio: sobre a função da vida imaginativa na teoria psicanalítica*
}

\author{
Thaís de Souza Teixeira
}

Trabalho teórico de enfoque psicanalítico, cujo objetivo é estudar os fenômenos de delírio, fantasia e devaneio de forma a compreender sua natureza e seus processos, mecanismos e funções dentro da dinâmica psíquica humana. Utilizam-se os casos de referência, "Homem dos ratos", o "Caso Schreber" e a " 'Gradiva' de Jensen”, além do artigo de Freud "Uma criança é espancada", para ilustrar as reflexões. Conclui-se que os três são conceitos estruturalmente diferentes, com processos, mecanismos e funções próprios, mas com aproximações que os tornam passíveis de confusão.

Palavras-chave: Delírio, fantasia, devaneio, neurose, psicose

* Artigo escrito a partir do trabalho de mesmo título vencedor do concurso "Ana Maria Popovic" de melhor Trabalho de Conclusão de Curso de 1999 pela PUC-SP. 


\section{Introdução}

O presente trabalho surgiu da necessidade de precisar conceitualmente em que consistem as fantasias e devaneios a que todos nos entregamos, de vez em quando, ao longo de nossas vidas.

Atividades como atendimento a pacientes psicóticos levantam questões sobre o funcionamento da vida imaginativa, tais como: Qual é a natureza do delírio? Quais as relações entre o devanear, o fantasiar e o delirar? Quais os limites entre cada um destes conceitos? Possuem todos o mesmo princípio? No que concerne às produções fantasiosas, onde termina a normalidade e começa a patologia? Neste sentido, quais os pontos de contato, neste campo, entre a neurose e a psicose - ou não há nenhum?

Não tive, é claro, a pretensão de esgotar todas estas questões, mas sim tornar mais claras algumas fronteiras e também pontos de contato entre os conceitos de delírio, fantasia e devaneio. Considerei, para isto, aspectos da neurose e da psicose, de forma a evitar o uso indiscriminado de conceitos que acabam, muitas vezes, sendo confundidos entre si.

Para melhor explicitar os mecanismos envolvidos nos fenômenos de delírio, fantasia e devaneio, baseei-me nos casos clínicos de Freud que, acredito, melhor elucidam estes conceitos. São eles o "Homem dos ratos", o "Caso Schreber" e a "“Gradiva' de Jensen", além do artigo de 1919, "Uma criança é espancada". O "Homem dos ratos" e o "Caso Schreber" serão relacionados ao delírio na neurose e na psicose, respectivamente, e a “'Gradiva' de Jensen”, por sua vez, será discutida no capítulo sobre devaneio. Já o material utilizado para a discussão do capítulo "Fantasia" será o artigo "Uma criança é espancada", que, mesmo não constituindo um caso clínico específico como os demais, será utilizado como o artigo de referência deste capítulo por sua extrema relevância com relação ao tema.

\section{O delírio na neurose e na psicose}

Analisaremos aqui o modo como a psicanálise compreende o fenômeno do delírio em formações patológicas neuróticas e psicóticas.

Freud (1924) assim descreve a diferença estrutural entre a neurose e a psicose: “... a neurose é o resultado de um conflito entre o ego e o id, ao 


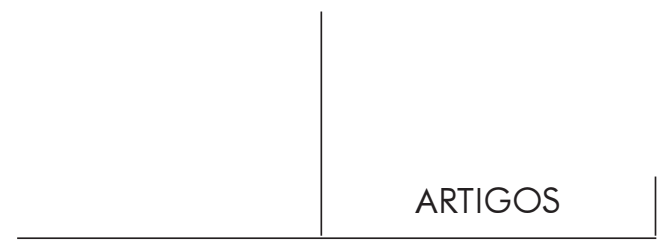

passo que a psicose é o desfecho análogo de um distúrbio semelhante nas relações entre o ego e o mundo externo". Esta definição é desenvolvida a partir da idéia de conflito e de defesa, segundo a qual o conflito se daria entre duas instâncias (ego $x$ id ou ego $x$ mundo externo), ao passo que a defesa seria investida contra as representações intoleráveis: recalque (Verdrangung) e rejeição (Ververfung).

Tal definição apresenta as duas grandes estruturas psíquicas dentro das quais pretende-se, neste estudo, destacar a função exercida pelo delírio, bem como suas semelhanças e diferenças fundamentais.

A neurose é compreendida pela psicanálise como tendo origem na luta do ego por manter afastado, recalcado, neutralizado, "soterrado" (para fazer uma alusão à "Gradiva") no id, um poderoso impulso dele proveniente, e que seja inaceitável pelas instâncias do ego e do superego (princípio de realidade). Em tal caso, o ego utilizase do mecanismo de recalque para defender-se deste impulso que, por sua vez, "luta contra esse destino" (Freud, 1924), criando caminhos (representações substitutivas) que se impõem ao ego mediante uma conciliação, e que constituem o sintoma. Sentindo-se ameaçado e prejudicado por ele, o ego continua a lutar contra o sintoma, tal como fez anteriormente contra o impulso. Este mecanismo constitui o quadro da neurose.

O que é essencial para a compreensão do fenômeno do delírio numa neurose é o conceito a ela diretamente ligado do recalque e, mais especificamente, do retorno do recalcado.

Muitas vezes confunde-se os termos repressão e recalcamento ${ }^{1}$ Pode-se dizer, mais especificamente, que o recalque seria o resultado da repressão exercida pelo ego sobre o material a ser confinado no id, e que, por sua vez, consistiria, tendo-se de fato efetuado o recalcamento, no material recalcado.

Uma vez isto colocado, pergunta-se: Onde estaria a relação do delírio com o recalque, ou com o seu retorno?

De Waelhens (1990) considera que, uma vez empreendido o recalcamento, este se deu sob a influência do real; se o objetivo desse recalcamento foi atingido, isto é, encerrar totalmente no inconsciente as pulsões e seus representantes psíquicos inaceitáveis, nenhuma neurose se instala. Quando, porém, o recalcamento é mais ou menos malogrado, ocorre um retorno parcial e disfarçado do recalcado - o sintoma

1. A tradução brasileira não distingue o termo Unterdrukung de Verdrangung, que correspondem à "repressão" e "recalque", respectivamente. Esta distinção é extremamente importante porque o primeiro termo refere-se à defesa que opera entre o cs e pcs, enquanto que a Verdrangung é a censura que opera entre os sistemas cs-pcs e ics. Neste sentido, é este segundo termo a verdadeira defesa que opera impedindo que as pulsões sexuais possam se manifestar, e ela opera modificando o sexual de forma a driblar a censura. 


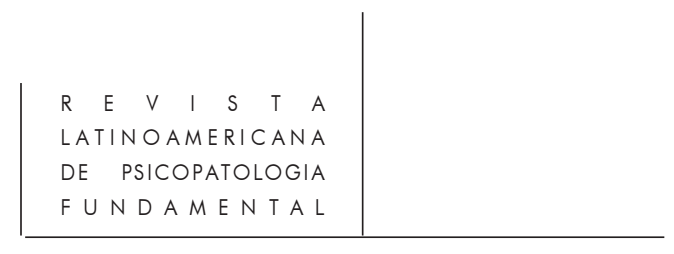

- com toda a angústia que causa uma tentativa de obter alguma satisfação de algo que se deva reprimir. A partir daí, o sujeito começará a buscar todos os recursos disponíveis que o mantenham, tanto quanto possível, afastado do campo litigioso, tal como o "Homem dos ratos", - ou retorno do recalcado) de que algo pudesse acontecer a seu pai e à dama de quem gostava. Isto se intensificou até ao ponto de o paciente desenvolver o delírio da dívida impagável ao Tenente A., cujo não cumprimento resultaria no castigo com os ratos sendo aplicado àquelas duas pessoas. Este delírio, segundo o paciente, atravessava sua mente "numa fração de segundos", e se lhe impunha como uma ameaça que ele tinha que evitar através de seus rituais. Segundo Safouan (1979), “... é o tempo do fracasso do recalcamento e do retorno do recalcado que define a neurose como tal e do qual resulta o afrouxamento das relações com a realidade. (...) A perda da realidade que aqui se produz refere-se precisamente a esse fragmento da realidade que desencadeou o conflito com o isso."

Vale aqui ressaltar as palavras de De Waelhens (1990), que salienta a diferença da fuga da realidade na neurose daquela que se dá nos casos psicóticos: segundo este autor, fugir da realidade, característica neurótica, é bem diferente de negá-la (caso da psicose). $O$ neurótico se afasta do real quando não pode mais fazer face ao que esse real lhe impõe. Entretanto, ao se comportar assim, ele de fato reconhece a realidade. Tal fuga, realizada pelo neurótico, nada tem a ver com o desconhecimento ou a foraclusão próprios do delírio psicótico, tanto que o neurótico a sente, ao mesmo tempo, como uma proteção e como uma limitação insuportável de sua existência.

No caso da psicose, os processos se desenvolvem de forma diferente. Segundo Freud (1924),

... a etiologia comum ao início de uma psiconeurose e de uma psicose sempre permanece a mesma. Ela consiste em uma frustração, em uma não-realização, de um daqueles desejos de infância que nunca são vencidos e que estão tão profundamente enraizados em nossa organização filogeneticamente determinada. Essa frustração é, em última análise, sempre uma frustração externa (...) O efeito patogênico depende de o ego, numa tensão conflitual desse tipo, permanecer fiel à sua dependência do mundo externo e tentar silenciar o id, ou ele se deixar derrotar pelo id e, portanto, ser arrancado da realidade.

Assim, na teoria freudiana, o mecanismo da psicose abrangeria uma retirada da libido enviada pelo ego, e essa libido sofreria um refluxo mais ou menos acentuado em direção ao próprio sujeito. Desta forma, ocorreria um desinvestimento do mundo externo e da realidade, e um superinvestimento libidinal do eu - o que, inclusive, ajuda

2. Vide "Notas sobre um caso de neurose obsessiva". 


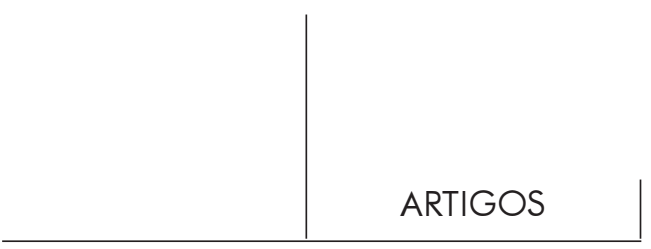

a explicar porque é tão comum o aparecimento de traços mais ou menos acentuados de delírio de grandeza na maioria dos casos de psicose de tipo paranóico ou esquizofrênico. Este mecanismo pode ser claramente percebido, por exemplo, no "Caso Schreber", ${ }^{3}$ em que o paciente "... ao mesmo tempo, consegue sozinho manter em xeque as ações de Deus, tornar-se o objeto do gozo sensual de Deus e gerar, por obra deste, uma nova humanidade" (De Waelhens, 1990: 71).

Há, ainda, muita controvérsia a respeito da psicose, sua origem e percurso, e sobre haver ou não, por exemplo, uma predisposição para ela. De Waelhens (1990) considera, com base no artigo de Freud de 1914, que tal processo seja relacionado a um narcisismo específico da psicose,

[... no qual esta retração dos investimentos objetais para o eu deve ser [concebida] ${ }^{4}$ como um estado secundário, construído com base num narcisismo primário que foi obscurecido por múltiplas influências. (...) Fundamentalmente, o investimento do eu persiste. Dito de outra forma, a psicose, ao menos de certo modo, pode ser descrita não tanto como um acidente, mas como o restabelecimento intensivo ou mesmo exclusivo de um regime que nunca deixou por completo de vigorar. Existem, pois, pulsões do eu voltadas para ele mesmo, que dele se desviam em algum momento, mas não inteiramente, e que podem retornar]. (Ibid.: 77)

Neste sentido, pode-se repetir a fórmula tão freqüentemente utilizada de que "o neurótico recalca o inconsciente, o psicótico recalca o real.” Esta idéia, juntamente com o conceito do investimento narcísico do eu, é importante para a compreensão, por exemplo, do desenvolvimento da psicose e do delírio de Schreber. De Waelhens (1990) afirma que, sendo verdade que o recalcamento é efetuado sob a pressão do real e que o investimento narcísico se desvia deste, é compreensível que as barreiras que se opõem à irrupção do inconsciente na consciência venham a ceder. É também muito importante observar que as fantasias e elementos (que, segundo Freud, só são identificáveis no neurótico no decorrer da análise, e que, por sua vez, povoam os enunciados conscientes e explícitos do psicótico) são transportados para o real de maneira mais estável e enraizada do que acontece no pseudo-real do sonho [e que constituirá o delírio]. Há uma diferença entre Schreber sonhando, pouco tempo antes de sua doença se manifestar, (que seria agradável ser mulher e submeter-se ao ato da cópula), e, na doença já manifesta, a experiência dessa transformação, que ele julgava passível de ser constatada por outrem.

O conceito de foraclusão, que situa a psicose como diferente do recalque da neurose, é essencial para a compreensão do delírio enquanto evidenciador do

3. Vide o "Notas psicanalíticas sobre um relato autobiográfico de um caso de paranóia".

4. Colchetes meus. 


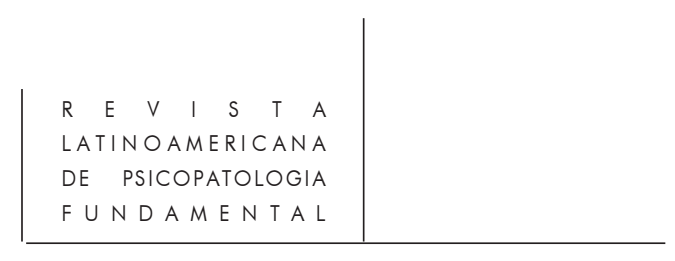

superinvestimento da representação verbal, própria da psicose, que constitui a tentativa de cura teorizada por Freud.

Freud observa, em casos de esquizofrenia, que muitas vezes a construção das frases do paciente psicótico sofre uma desorganização que as torna absurdas (e que é característica de muitas formas de delírio); a partir disso, Lacan, então, situa este fato como uma alteração na relação entre o significante e o significado, entre o sentido de uma expressão e a imagem que o exprime, alteração esta causada pela quantidade de investimento libidinal dirigida a cada representação (de objeto e de palavra).

A primeira teoria do aparelho psíquico faz uma distinção no sistema consciente entre a representação do objeto e a da palavra que designa este objeto. Na psicose, o investimento da primeira desaparece, enquanto que o da segunda, não só se mantém, como se torna superinvestido. Freud presumiu que, em regra geral (na "normalidade"), a representação consciente engloba a representação da coisa $e$ mais a representação da palavra, ao passo que o inconsciente engloba apenas a representação da coisa. Na "normalidade", não havendo motivo para recalcamento, seria de se esperar que o pré-consciente estabelecesse uma comunicação entre a representação do objeto (coisa) e a de seu nome (palavra), transmitindo a este último o investimento afetivo do primeiro. Na neurose, o recalque consistiria em proibir essa transmissão, impedindo a possibilidade de ligação. Assim, o objeto continuaria investido no inconsciente, mas este investimento não passaria para sua representação verbal, de modo que o neurótico nunca tomaria conhecimento da carga libidinal que o objeto recalcado (cujo nome ele conhecia) teria em seu inconsciente.

De Waelhens (1990: 81) precisa “... que o que se chamava recalcamento, em matéria de psicose, devia ser um mecanismo absolutamente diferente, pois levava a retirar o investimento do objeto no próprio cerne do inconsciente, ao passo que subsistia ou aumentava o investimento da representação verbal".

Freud faz uma retificação em 1911, por ocasião de seu estudo sobre o caso Schreber: "Foi incorreto dizer que o sentimento reprimido dentro fosse lançado para fora; deveríamos antes dizer, como agora vemos, que o que foi abolido no interior retorna desde fora." Segundo Safouan (1979), o que é abolido não é mais a "realidade exterior"; tampouco é o "entreposto do imaginário" do qual o sujeito, ao contrário, toma emprestado materiais destinados a suprir esta abolição. Assim, resta o simbólico, o que leva Lacan a definir o termo foraclusão através da fórmula: “... o que é foracluído do simbólico retorna no real."

Este retorno no real, mencionado por Lacan, constitui um segundo movimento, conseqüente ao desinvestimento sofrido por esse real tão ameaçador para o sujeito, e que nada mais é do que a tentativa de reinvestir o real (tentativa de cura), mas de modo delirante. O que ocorre, segundo De Waelhens (1990), é que o significante é instalado no real e superinvestido, a partir do momento em que esse mesmo 


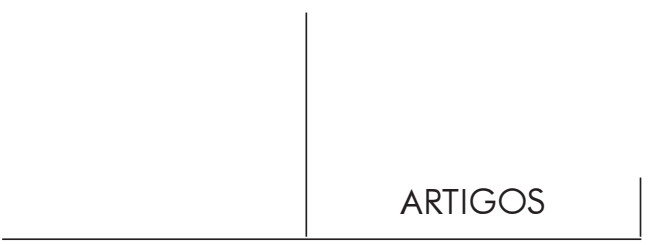

significante é excluído do inconsciente e a carga libidinal ligada a seu significado é retirada dele e reconduzida para o eu. Uma parte desta passa a ser, então, despendida em favor da palavra. O doente procura reinvestir as coisas e, para chegar a isso, começa por investir as palavras, porém sem conseguir mais ir além delas em direção às coisas. Segundo Freud (1911) em suas considerações sobre Schreber, “... o paranóico reconstrói o universo, de fato não mais esplêndido, mas ao menos tal em que possa de novo viver. Ele o reconstrói mediante seu trabalho delirante. Aquilo que tomamos por uma produção mórbida, a formação do delírio, é na realidade uma tentativa de cura, uma reconstrução." Como exemplo, pode-se citar o próprio Schreber, ao afirmar que o universo "sofreu uma profunda modificação interna", relacionada a "catástrofes" que ocorreriam no fim do mundo. Em 1911, Freud relaciona os freqüentes delírios de "fim de mundo" dos pacientes psicóticos ao refluxo libidinal efetuado do real em direção ao eu: “... o fim do mundo é a projeção dessa catástrofe interna, pois o universo subjetivo do doente chegou ao fim desde que ele lhe retirou o amor." Ainda sobre este delírio, ou "vivência de fim de mundo", De Waelhens (1990: 73) completa: "Esse desbotamento, esse desmoronamento, não passa da experiência, no real, da retração dos investimentos libidinais objetais do enfermo, retração que é característica da 'psicose narcísica', e os investimentos retirados dos objetos são retransportados, além disso, para o próprio eu".

Um bom argumento para a consideração do fenômeno do delírio como tentativa de cura também está na comparação da gravidade dos casos de pacientes delirantes com pacientes não delirantes. De Waelhens (1990) afirma que os pacientes (no caso, esquizofrênicos) não delirantes são justamente aqueles cujo prognóstico é mais sombrio, porque a ausência de delírio prova que a retração narcísica não é combatida por coisa alguma, que o "recalcamento" em que ela consiste reina completamente, uma vez que não se manifesta nenhuma tentativa de reinvestimento objetal. Entretanto, a psicanálise vai mais além na determinação das funções do delírio, considerando também seus outros papéis. De Waelhens (1990), em consonância com diversos outros autores, afirma que não se pode reduzir todos os delírios a uma tentativa do sujeito de se agarrar a restos de realidades, anteriormente investidas, para combater o "recalcamento" autista. O que também aparece nos delírios seria, assim, e preferencialmente, uma realização fictícia de desejos que seriam inconscientes no estado normal e os quais "longe de poderem restaurar um vínculo qualquer com a realidade, são, ao contrário, essencialmente realitätswidrig ['avessos à realidade']" (p. 75).

No "Homem dos ratos", pode-se compreender sua relação com a realidade insuportável através do restabelecimento das conexões entre os elementos da rede associativa, que se estabeleceu na mente do jovem e o levou a relacionar a dívida com o castigo dos ratos, cuja ligação ele não podia compreender (porque, de fato, "não 


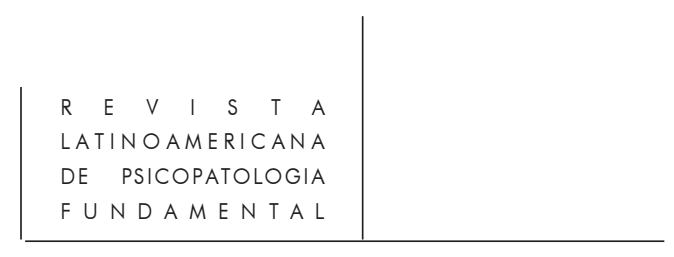

se lembrava"). Ao longo da análise, pôde-se chegar à conclusão de que todas as relações se estabeleceram a partir da palavra Raten (do alemão, prestações), que se assemelha com Ratten (ratos, ratazanas); esta palavra, por sua vez, está na raiz de Spielratte (rato de jogo), que também assemelha-se a Heiraten (casamento). A análise de Freud levou-o à conclusão de que um evento ocorrido na infância do paciente, no qual ele havia mordido seu irmão, fê-lo associar seu ato de morder ao ato de morder de um rato, que, segundo Freud, “... possui dentes afiados, com os quais rói e morde." Desta maneira, o paciente associou "ratos" a "crianças". Imbricados nestes dados, estão aqueles em que o pai do paciente era um homem que gostava de jogar, era um Spielratte, e contraiu, em função disso, uma dívida de jogo. A palavra Raten, significando prestações, e portanto relacionada à dívida, foi a ponte que ligou "ratos" a "dinheiro" (a "moeda-rato") na mente do paciente. Daí surgiu a conexão entre "crianças" (que eram "ratos") e "dinheiro", de forma que o paciente introduziu a questão do dinheiro na sua relação com o pai - o pai que devia dinheiro por ser um Spielratte, falhou na função paterna, pois seu único interesse era o jogo, e não o filho. Há, entretanto, a presença de uma marca pulsional, de um significante, que possibilita a estrutura neurótica desenvolvida pelo paciente. A crítica e a mágoa do jovem com relação ao comportamento de seu pai estava relacionada com o despertar de seu comportamento obsessivo, porque a situação do pagamento impossível da dívida ao Tenente A. ecoava em sua mente como uma analogia a uma situação antiga de uma dívida de jogo não saldada por seu pai. E, da mesma maneira como aconteceu a seu pai quando era um jovem oficial do exército, o paciente se via atualmente na situação de estar dividido entre o afeto de duas mulheres. Na época, seu pai teve de decidirse entre uma mulher rica e uma pobre. Assim, "casar-se por dinheiro" foi outra ligação ocorrida na mente do rapaz, que, desta forma, associou em um quadro simbólico inconsciente todos os representantes de significantes Heiraten - Raten Spielratte - Ratten. Toda esta cadeia associativa era completamente inconsciente, tudo que o paciente compreendia era que "se não pagasse ao Tenente A., o castigo dos ratos seria aplicado a seu pai e à dama." Nisto consistia o seu delírio.

Por ser, porém, neurótico, e não psicótico, o paciente em questão sofre não só com o peso, mas também com o absurdo de seu delírio (ou sintoma), pois sabe que não é normal ouvir estas ordens; assim, julga-se doente e procura ajuda. Não é, por outro lado, o que acontece com Schreber em sua psicose.

A perseguição que Flechsig exercia sobre sua pessoa restituía a Schreber um certo "real", á medida que consistia numa "saída intermediária" encontrada pelo paciente. Esta saída garantia a Schreber dar vazão à explosão de seu impulso homossexual reprimido, o que lhe permitia obter alguma satisfação traduzida numa forma que ele pudesse suportar - a saber, na forma dissimulada que inverte amor em ódio (e que, por si, já denota uma ligação, ainda que tênue, com o real, uma vez que 


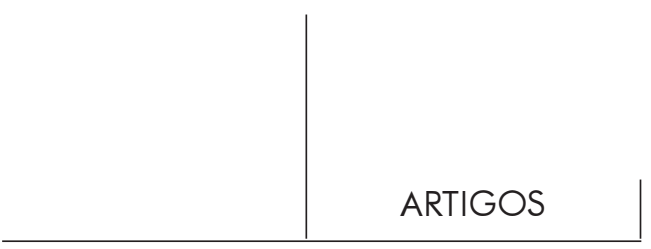

o delírio do paciente se mantém minimamente compatível com suas próprias concepções morais) - evitando, ao mesmo tempo, o "recalcamento" autista cuja gravidade foi anteriormente mencionada (e que representa, portanto, uma tentativa de reinvestimento objetal, ou, em outras palavras, de cura).

Diferentemente do caso do Homem dos ratos, Schreber ingressou numa psicose; no seu psiquismo não há uma marca pulsional, um significante da função paterna. O Outro de Schreber é um "Outro infinito", não existe o significante para ele e, por isso, pode-se compreender que o paciente em questão tenha procurado "tamponar este buraco" colocando Deus no lugar do pai, por uma via delirante. Por isso, ele tem absoluta convicção da realidade de seu delírio. Para Schreber, os nervos são nervos, os vestíbulos do céu são vestíbulos do céu etc. Esta certeza tão marcante na psicose deve-se, segundo Safouan (1979), ao apagamento da função metafórica que, por sua vez, é o traço distintivo que separa a estrutura neurótica daquela da psicose.

\section{Fantasia}

Segundo Laplanche \& Pontalis (1986), o termo alemão Phantasie designa a imaginação. Não tanto a faculdade de imaginar no sentido filosófico do termo (Einbildungskraft), mas sim o mundo imaginário, os seus conteúdos, a atividade criadora que o anima (das Phantasieren). Existe muita controvérsia sobre os termos que designam o fenômeno da fantasia e o uso que se faz deles. Em francês, fantasme (fantasma) voltou a ser posto em uso pela psicanálise, e, como tal, encontra-se mais carregado de ressonâncias psicanalíticas do que o seu homólogo alemão. Por outro lado, não corresponde exatamente ao termo alemão, visto que sua extensão é menor. Designa determinada formação imaginária e não o mundo das fantasias, a atividade imaginativa em geral. Já o sentido antigo do termo fantaisie (fantasia), cuja retomada foi proposta por Daniel Lagache, tem a vantagem de designar ao mesmo tempo uma atividade criadora e as produções, mas, por outro lado, dificilmente pode deixar de sugerir, para a consciência lingüística contemporânea, os sentidos de capricho, originalidade, ausência de seriedade etc.

O conceito de fantasia alude, segundo Mezan (1982), a um dos eixos mais importantes do pensamento freudiano: a oposição entre "realidade psíquica" e "realidade material". Por "realidade psíquica", alerta, não se deve entender o mundo interior da psicologia introspectiva, ou, como refere Laplanche \& Pontalis (1986), o "campo psicológico". O termo "realidade" deve ser tomado no seu sentido forte, ou seja, como algo dotado de organização, estabilidade e eficácia, e cujas modalidades de operação a psicanálise se esforça por descobrir. A fantasia é o cenário do desejo; a existência de cenários típicos, como o sádico, o masoquista, o "romance familiar", 
sugerem a Freud a noção de "fantasias originárias", que organizam a vida fantasmática do sujeito independentemente de suas experiências pessoais. Desta forma, pertencem ao rol das fantasias originárias a cena de sedução, a cena do coito parental, a castração etc.

Segundo Laplanche e Pontalis (1986), pode-se distinguir na obra de Freud diversos níveis de fantasia (ainda que o autor não o faça explicitamente, e ainda que em psicanálise o termo "fantasma" e "fantasia" tenham um emprego muito extenso - Freud utiliza Phantasie). Tais níveis difeririam em termos de consciente, subliminar e inconsciente.

1. Nivel consciente: O que se conhece por sonhos diurnos, cenas, episódios, romances, ficções, que uma pessoa forja e conta a si mesma em estado de vigília, Freud denomina Phantasien. É a partir do modelo dos sonhos diurnos que Freud, em A interpretação dos sonhos (1900), descreve as fantasias. Compreende-as como formações de compromisso e compara sua estrutura com a dos sonhos. Estas fantasias ou sonhos diurnos são utilizados pela elaboração secundária, fator do trabalho do sonho que mais se aproxima da atividade vigilante.

2. Nivel subliminar: Freud utiliza-se freqüentemente da expressão "fantasia inconsciente", embora tal expressão provoque algumas confusões devido a não ter sempre uma posição metapsicológica bem definida. Assim, ela é às vezes compreendida como um devaneio subliminar, pré-consciente, a que a pessoa se entrega e do qual irá ou não tomar consciência. As fantasias inconscientes são consideradas por Freud como precursoras dos sintomas histéricos e são descritas no artigo "Fantasmas histéricos e sua relação com a bissexualidade" (1908) como estando em estreita conexão com os sonhos diurnos.

3. Nivel inconsciente: Seguindo uma linha de pensamento diversa, a fantasia aparece como estando em conexão muito mais íntima com o inconsciente. É no capítulo VII de A interpretação dos sonhos (1900) que Freud situa a um nível inconsciente, no sentido tópico do termo, certos fantasmas (fantasias): os ligados ao desejo inconsciente e que estão no ponto de partida do processo metapsicológico de formação dos sonhos. Assim, a primeira parte do "trajeto" que leva ao sonho vai, nas palavras de Freud, “(...) progredindo das cenas ou fantasmas (fantasias) inconscientes até ao pré-consciente".

Laplanche e Pontalis (1986) pontuam o fato de que Freud não parece muito preocupado em estabelecer as distinções acima mencionadas, mas sim em insistir, por outro lado, nas ligações entre os diferentes níveis de fantasia, assinalando as analogias, as relações estreitas, as passagens entre eles. Assim, salientam a afirmação de Freud:

As fantasias claramente conscientes dos perversos - que, em circunstâncias favoráveis, podem transformar-se em comportamentos estruturados; os temores delirantes dos paranóicos - que são projetados sobre outros com um sentimento hostil; 


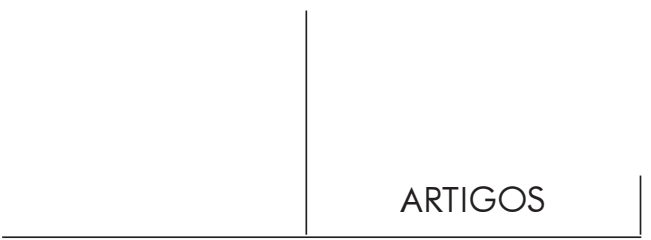

as fantasias inconscientes dos histéricos - que se descobrem pela psicanálise por detrás dos seus sintomas -, todas essas formações coincidem no seu conteúdo até aos mínimos detalhes.

\section{E completam:}

Em formações imaginárias e estruturas psicopatológicas tão diversas como as que são por Freud aqui designadas, pode encontrar-se um mesmo conteúdo e uma mesma estrutura, conscientes ou inconscientes, agidos ou representados, assumidos pelo indivíduo ou projetados sobre outrem.

No âmbito da investigação psicanalítica, procuram-se os fantasmas ou fantasias que subjazem por detrás das produções do inconsciente como o sonho, o sintoma, o agir, os comportamentos repetitivos etc. Surgem, assim, aspectos do comportamento muito distantes da atividade imaginativa que, mais tarde, acabam também por mostrar-se "derivados" de fantasmas ou fantasias inconscientes. Nesta perspectiva, segundo Laplanche e Pontalis (1986),

... é o conjunto da vida do indivíduo que se revela como modelado, estruturado por aquilo a que se poderia chamar, para sublinhar o seu caráter estruturante, uma fantasmática. Esta não deve ser concebida apenas como uma temática, ainda que caracterizada para cada indivíduo por traços eminentemente singulares; ela compreende o seu dinamismo próprio, pois as estruturas fantasmáticas procuram exprimir-se, encontrar uma saída para a consciência e para a ação, e constantemente atraem para si um novo material.

Existe um certo número de traços constantes que caracterizam a fantasia e marcam a sua estreita relação com o desejo - pois consiste na encenação do desejo a função primitiva da fantasia. São estes traços: uma dramatização visual, com cenas organizadas, em que o sujeito está sempre presente; uma sintaxe própria, capaz de sofrer permutações de função (como a fantasia homossexual "Eu o amo" do caso Schreber, ou a fantasia sádica "Uma criança é espancada", a ser aqui discutida); e marcas de operações defensivas, tais como a projeção, a negação, a transformação no contrário etc. Vê-se aí, na presença destas defesas nas próprias fantasias, a presença da "proibição", da interdição, no coração mesmo do desejo (Mezan, 1982; Laplanche e Pontalis, 1986).

A interdição, conforme acima mencionado, encontra-se, portanto, na raiz das fantasias. Veremos a seguir como esta interdição é viabilizada pelo fenômeno do recalque, essencial, por sua vez, para a compreensão da estrutura das fantasias.

Sabe-se que durante o processo de desenvolvimento normal, a libido, antes ligada às zonas erógenas das fases mais primitivas, a saber, oral, anal e fálica, passa a se ligar, com o desfecho do Édipo, à zona genital. Assim, poderá aflorar a sexualidade "normal", processo segundo o qual os sentimentos edipianos sucumbem 


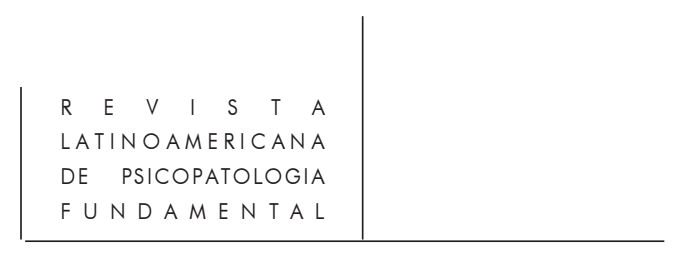

à força da realidade e o indivíduo torna-se capaz de estabelecer novas relações de objeto. Entretanto, quando por fatores específicos ocorrem falhas neste processo de desenvolvimento e suas etapas não são vencidas de forma satisfatória, ocorrem rearranjos no investimento desta carga libidinal que determinarão no indivíduo uma estruturação de base psicopatológica.

Tendo-se em conta estes princípios retomados, pode-se compreender que, no caso de falhas no processo de desenvolvimento (em que a libido não pode ser adequadamente canalizada para a zona genital), existam, segundo Mezan (1982), duas outras possibilidades de destino para esta libido: ou ela permanece ligada às zonas erógenas anteriores (oral, anal ou fálica), resultando em perversões; ou, depois de ter chegado à etapa genital, fatores específicos a impedem de se fixar nesta região, e o recalque se encarrega de fazê-la refluir para as zonas abandonadas. Porém, o mesmo recalque impede o surgimento da perversão correspondente (à zona em que a libido se fixou); impedida de "atuar" (descarregar-se) por um ato perverso, ou de "traduzirse em termos psíquicos" (aceder à consciência), a libido então adere a fantasias de natureza inconsciente, ou seja, recalcadas, que contribuem para formar os sintomas neuróticos. Este é o sentido do fenômeno de "regressão", mencionado numa carta de 1897 (carta 75) de Freud a Fliess: a libido retorna aos canais de onde fluíra para a zona genital.

Estas duas possibilidades permitem-nos compreender a famosa frase "as neuroses são o negativo das perversões", no sentido de que o perverso expõe, manifesta externamente, aquilo que o neurótico apenas guarda em suas fantasias.

No artigo “"Uma criança é espancada' - Uma contribuição ao estudo da origem das perversões sexuais" (1919), Freud discute detalhadamente a origem de um tipo particular de perversão: o masoquismo. Para isto, utiliza os exemplos deste artigo para ilustrar os casos (segundo ele bastante freqüentes) de pacientes que procuram tratamento analítico para a histeria ou uma neurose obsessiva e que confessam haverse abandonado à fantasia: "Uma criança é espancada".

Trata-se aqui de uma fantasia de origem totalmente inconsciente. Ao longo do artigo, Freud demonstra que a fantasia "Uma criança é espancada", estudada basicamente no caso de pacientes do sexo feminino, passa por três fases de desenvolvimento, das quais a primeira e a terceira são lembradas conscientemente, ao passo que a segunda permanece inconsciente.

Esta fantasia apresenta-se invariavelmente catexizada com um alto grau de prazer e tem sua descarga num ato de agradável satisfação auto-erótica. A visão real de uma criança sendo espancada é, ao contrário, extremamente desagradável às pessoas que relatam esta fantasia.

As três fases da fantasia podem ser compreendidas como três variações da frase "uma criança é espancada". Cada fase possui o seu significado e todas elas têm 


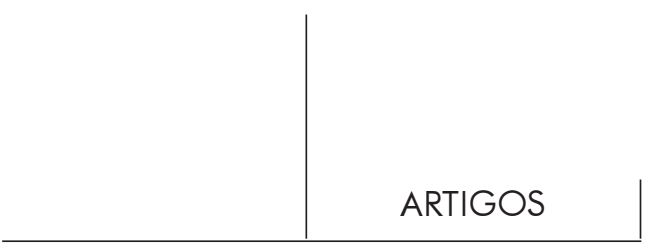

a função de encobrir o conteúdo recalcado da vida sexual da criança (o desejo da menina pelo pai), seja através das mudanças sintáticas da frase ou do seu ocultamento no inconsciente (no caso da segunda fase). Freud compreende a fantasia em questão como sendo de natureza sádica nas duas fases conscientes (primeira e terceira) e de natureza masoquista na fase inconsciente (a segunda). Vale aqui ressaltar a observação de Freud, a partir da análise cuidadosa dos casos, de que a terceira fase é sádica apenas em sua aparência, pois a satisfação que dela resulta é de caráter masoquista.

Freud localiza a raiz do interesse pelas fantasias de espancamento no processo de desenvolvimento sexual infantil - mais precisamente no final ou após o término do período de determinação dos complexos compreendido entre os dois e os quatro ou cinco anos de idade. Por motivos constitucionais, um dos componentes da função sexual desenvolveu-se precocemente, à frente do resto. Segundo Freud (1919), este componente "... tornou-se prematuramente independente, sofreu uma fixação, sendo por isso afastado dos processos posteriores de desenvolvimento, e, dessa forma, dá evidência de uma constituição peculiar e anormal no indivíduo."

Em um primeiro momento, quando a fantasia é apresentada, quem espanca a criança é um adulto de identidade obscura e a criança não é jamais a que cria a fantasia, mas invariavelmente outra criança, com mais freqüência um irmão ou uma irmã, se existem. Depois se esclarece que o adulto a princípio desconhecido é o pai, e a criança que apanha é uma criança odiada pela menina, representação do seu ódio e ciúme perante os objetos que desviem dela o amor paterno. Assim, a frase da primeira fase pode então ser compreendida como: "O meu pai não ama essa outra criança, ama apenas a mim". A visão desta cena lhe traz, desta forma, uma grande satisfação, o que caracteriza sua natureza sádica.

Mas o inevitável fracasso de seu amor incestuoso acaba acontecendo. Não se pode evitar o destino do recalque e, por uma razão ou outra, a criança é obrigada a recusar a escolha objetal anterior. Segundo Freud (1919), "Na nova fase, nenhum produto mental dos impulsos de amor incestuosos que esteja inconscientemente presente é assumido pela consciência; e nada que já tenha alcançado a consciência é dela expulso." O que ocorre é o surgimento de um sentimento de culpa, indubitavelmente ligado à permanência, no inconsciente, dos desejos incestuosos da fase anterior. É então que se dá a inversão da frase, e o pai da menina não está mais batendo na outra criança, mas está, como castigo provocado pelo sentimento de culpa, batendo nela própria. Agora, portanto, as palavras são: "Estou sendo espancada pelo meu pai”, de caráter inequivocamente masoquista - a fantasia é acompanhada por um alto grau de prazer. Segundo Freud (1919), esta segunda fase é a mais importante e a mais significativa de todas. "Pode-se dizer, porém, que, num certo sentido, jamais teve existência real. Nunca é lembrada, jamais conseguiu tornar-se consciente. É uma construção da análise, mas nem por isso é menos uma necessidade." 


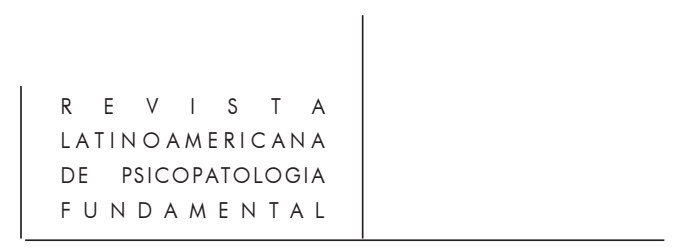

A terceira fase assemelha-se novamente à primeira. A pessoa que bate não é mais o pai: ou ela é deixada indeterminada, como na primeira fase, ou transforma-se numa outra figura de autoridade, como um professor, por exemplo. E a criança que apanha, por sua vez, não é mais a que cria a fantasia, como na segunda fase. Nesta fase, as fantasias tornam-se muito mais elaboradas, saindo da situação monótona do simples espancamento e passando por situações bem mais complexas, que envolvem castigos e humilhações de outra natureza que, muitas vezes, substituem o próprio espancamento. Esta terceira fase é atingida com o tempo, e desperta atividades da imaginação que assumem já a forma de "devaneios". O que mantém uma forte ligação entre esta fase e a fase intermediária é o fato de haver agora uma forte e inequívoca excitação sexual ligada à fantasia, que proporciona, assim, um meio para a satisfação masturbatória.

"O meu pai me ama" possui um sentido genital, sendo convertido, devido ao recalque, nas palavras "O meu pai está me batendo (estou sendo espancada pelo meu pai)". O sentido de "ser espancada" está na convergência do amor sexual e do sentimento de culpa. Assim, o espancamento consiste não apenas no castigo pela relação genital proibida, como também no próprio substituto daquela relação. $\mathrm{O}$ espancamento, portanto, toma o lugar de um ato sexual. Este é o sentido expresso por essa fantasia, que permanece inconsciente, segundo Freud (1919), provavelmente devido à intensidade do recalque.

\section{Devaneio}

O termo "fantasia" é muitas vezes utilizado com o sentido de "devaneio", sendo este último, de maneira geral, englobado na conceituação do primeiro. Laplanche e Pontalis (1986) salientam esta generalização do termo fantasia ao distinguirem seus diversos níveis 5 . Sobre o que aqui se entende por devaneio, afirmam que Freud designa sob o nome de Phantasien, em primeiro lugar, os sonhos diurnos, cenas, episódios, romances, ficções, que o indivíduo forja e a si mesmo conta no estado de vigília. Em A interpretação dos sonhos (1900), é com base no modelo dos sonhos diurnos que Freud descreve as fantasias. Ainda segundo Laplanche e Pontalis (1986: 230), Freud “... analisa-as [as fantasias] como formações de compromisso e mostra que a sua estrutura é comparável à do sonho. Estes fantasmas (fantasias) ou sonhos diurnos são utilizados pela elaboração secundária, fator do trabalho do sonho que mais se aproxima da atividade vigilante".

Dizer que devanear é como "sonhar acordado" não é apenas uma bela metáfora sem maiores razões de ser. Naguera (1969) pontua que os devaneios ou divagações

5. Vide seção anterior. 


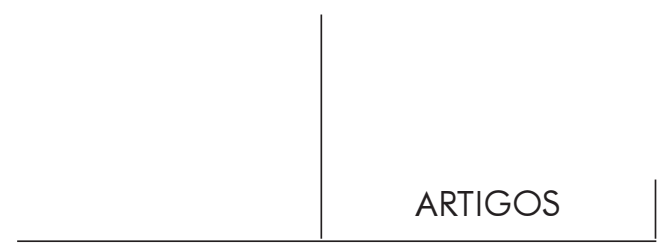

diurnas compartilham com os sonhos noturnos de um grande número de suas propriedades, e que a investigação dessas fantasias poderia, de fato, ter servido a Freud em A interpretação dos sonhos (1900) como a melhor e mais curta abordagem para a compreensão do sonho. Assim, tal como os sonhos, os devaneios são realizações de desejos e baseiam-se, em elevado grau, em impressões de experiências infantis. Tal como os sonhos, eles se beneficiam de uma certa medida de relaxamento da censura (Naguera, 1969).

Existem, contudo, diferenças básicas entre os devaneios e os sonhos, que dizem respeito à sua relação com a realidade. Segundo Freud (1900), nos sonhos, “... atribuímos completa crença às alucinações... É essa característica que distingue os verdadeiros sonhos do devaneio, que nunca é confundido com a realidade" (Naguera, 1969). Assim, pode-se dizer que os devaneios seriam uma forma de pensamento durante a vida desperta que tem lugar no consciente ou no pré-consciente e obedece às suas leis próprias, possuindo suas peculiaridades. Já os sonhos seriam manifestações de conteúdos inconscientes, latentes, que ingressam na consciência durante o sono através de mecanismos como, por exemplo, a distorção. Estes mecanismos são condição essencial para que tais conteúdos inaceitáveis (e por isso inconscientes) possam driblar o recalque e aceder à consciência.

De forma sucinta, pode-se dizer que os devaneios diferem das fantasias inconscientes recalcadas, à medida que os primeiros são fenômenos que têm lugar no consciente ou no pré-consciente, diferentemente das fantasias mencionadas, cujo núcleo central encontra-se no inconsciente. Isto não quer dizer que os devaneios não tenham uma forte ligação com o inconsciente. Os conteúdos dos devaneios também têm suas raízes neste arsenal inconsciente, e é esta a razão pela qual o ato de devanear pode ser tão prazeroso - porque ele tem a mesma função de via de satisfação de desejos, tal como o delírio, as fantasias inconscientes ou os sonhos (guardadas as diferenças de vias de expressão e mecanismos psíquicos envolvidos, além das demais diferenças de funções entre estes fenômenos).

Freud, em seu artigo de 1907, "Escritores criativos e devaneios", procura nas brincadeiras ou jogos infantis os primeiros traços de atividade imaginativa. Propõe que a criança, ao brincar, se comporta à maneira de um escritor criativo, criando um mundo próprio, ou melhor, reajustando os elementos de seu mundo de uma nova forma que lhe agrade. Ele pontua que a criança sempre leva esta atividade muito a sério, despendendo nela muita emoção. E salienta: "A antítese de brincar não é o que é sério, mas o que é real." Mesmo com toda a emoção com que catexiza seu mundo de brinquedo, a criança o diferencia perfeitamente da realidade, e gosta de ligar seus objetos e situações imaginados às coisas visíveis e tangíveis do mundo real, sendo esta conexão tudo o que distingue o "brincar" infantil do "fantasiar" (Freud, 1907).

Quando a criança cresce, ela pára de brincar. Freud (1907) coloca que “... nada é tão difícil para o homem do que abdicar de um prazer que já experimentou.” Assim, 


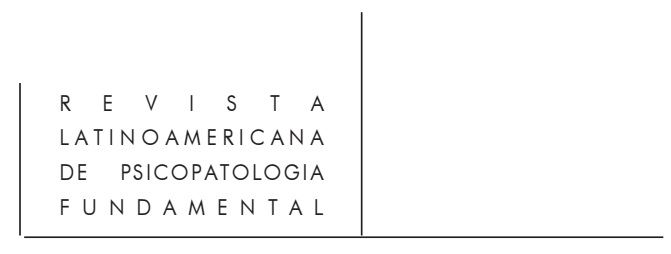

a criança na verdade não renuncia a este prazer, mas o troca por outro. Ela apenas abdica do elo com os objetos reais. Nas palavras de Freud (1907),

... em vez de brincar, ela agora fantasia. Constrói castelos no ar e cria o que chamamos de devaneios. Acredito que a maioria das pessoas construa fantasias em algum período de suas vidas. Este é um fato a que, por muito tempo, não se deu atenção, e cuja importância não foi, assim, suficientemente considerada.

O brincar das crianças é, portanto, substituído pelo devanear dos adultos. Entretanto, enquanto a criança brinca abertamente sem inibições, o adulto, por sua vez, envergonha-se de suas fantasias, escondendo-as dos outros e guardando-as para si como algo extremamente íntimo. Freud (1907) afirma que o que se passa com o adulto é que, frente às pressões sociais que lhe exigem que pare de brincar ou fantasiar e passe a atuar no mundo real, e dada a natureza de alguns dos desejos que provocaram suas fantasias, ele se vê obrigado a escondê-las e envergonha-se delas, por serem infantis e proibidas.

Sabe-se que as forças motivadoras do fantasiar (no sentido de devanear) são os desejos insatisfeitos, trata-se de uma realização de desejo, uma correção da realidade insatisfatória. Freud (1907) propõe que os desejos motivadores variam conforme o sexo, o caráter e as circunstâncias da pessoa que fantasia, dividindo-se naturalmente em dois grupos principais, que seriam: desejos ambiciosos, que se destinam a elevar a personalidade do sujeito e os desejos eróticos (freqüentemente as duas tendências encontram-se unidas). Porém, o próprio autor alerta para que não se suponha, com isso, que os produtos da atividade imaginativa - que é o devanear - sejam estereotipados ou inalteráveis. "Ao contrário - afirma - adaptam-se às impressões mutáveis que o sujeito tem da vida, alterando-se a cada mudança de sua situação e recebendo de cada nova situação uma espécie de "carimbo de data de fabricação'." Deve-se considerar, ainda, a importância da relação entre o devaneio e o tempo. É como se o devaneio se desse entre três tempos - "os três momentos abrangidos pela nossa ideação" (Freud, 1907). Estes três tempos articulam-se entre uma impressão atual, ou seja, uma ocasião motivadora do presente capaz de despertar um dos desejos principais do sujeito que, retrocedendo à lembrança de uma experiência correspondente do passado, geralmente infantil, em que esse desejo foi realizado, cria uma situação projetada para o futuro que representa a realização do desejo. Assim, dá-se origem a um devaneio ou fantasia (remetido ao futuro) que encerra traços da sua origem a partir da ocasião que o provocou (presente) e a partir da lembrança (passado). Desta forma, passado, presente e futuro "são entrelaçados pelo fio do desejo que os une" (Freud, 1907).

Quando um devaneio ou fantasia, fenômeno natural do funcionamento mental humano, pode tornar-se patológico? Freud (1907) considera que quando as fantasias se tornam exageradamente profusas e poderosas, estão presentes as condições para 


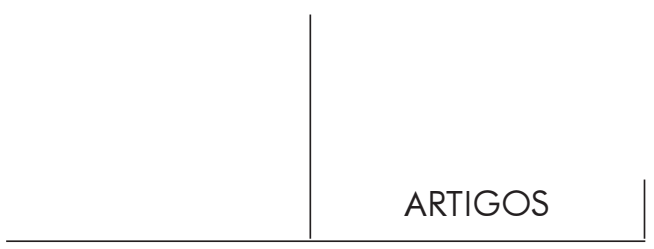

o desencadeamento da neurose ou da psicose. Ele afirma que “... as fantasias também são precursoras mentais imediatas dos penosos sintomas que afligem nossos pacientes, abrindo-se aqui um amplo desvio que conduz à patologia."

O caso apresentado no artigo "Delírios e sonhos na 'Gradiva' de Jensen" (1907) é um exemplo de devaneio que fugiu ao controle do indivíduo e assumiu as proporções de um delírio.

Na escultura denominada "Gradiva", uma figura feminina está caminhando para o lado, com um passo bastante peculiar. Sklar (1989), ao comentar o sentido psicanalítico de determinadas obras de arte e sua relação com o autor e o espectador, afirma que, no caso da "Gradiva", o espectador cria uma fantasia (devaneia) a partir de elementos presentes na escultura que suscitam a sua imaginação. Ele assume, então, uma postura ativa com relação à "Gradiva", à medida que, ao contemplar a figura caminhando, é levado, por exemplo, a imaginar o que a faz movimentar-se naquela direção. A sua percepção o mantém a uma certa distância da imagem gravada, e este distanciamento, que o detém por um momento, o faz sentir que precisa se fixar nesta atitude para poder decifrar o movimento apresentado.

Em tal atitude, o espectador procura inicialmente criar uma cena que lhe esclareça o sentido daquele movimento. Logo percebe que está faltando algo na imagem que só ele próprio pode revelar. Em razão disso, ele, espectador, participa efetivamente do que ali está representado (Sklar, 1989). É este mesmo processo que ocorre com o protagonista da obra de Jensen quando vê a "Gradiva" pela primeira vez, numa escultura em baixo-relevo.

Norbert dá à escultura o nome de "Gradiva", que significa "a que avança" e deduz, a partir de seus traços, que ela seria de origem helênica. Sklar (1989) aponta que estas observações sobre os traços da personagem estão ligadas a uma fantasia que implicitamente traz a idéia de que o espaço pode ter uma linguagem própria. Este dado liga-se também a uma outra observação do mesmo autor, que refere a “indissolúvel comunhão" criada por Norbert entre ele e a escultura, de forma que ela se tornou uma parte de seu mundo exterior. Após vê-la simbolicamente em diversas situações, seja nos pés das mulheres nas ruas ou nos seus próprios sonhos, ele passou a estabelecer com a imagem da "Gradiva" uma relação em que ela se tornou eterna, "pois o símbolo não morre, mas, ao contrário, persiste" (p. 60). Pode-se perceber o sentido oceânico da "Gradiva" pela extensão que ela assume na fantasia de Norbert, pois este sentido torna-se tão grande que é capaz de deslocar aquela imagem para um outro lugar: Pompéia. É justamente esta imagem que dá algum sentido ao movimento percebido na escultura (Sklar, 1989).

Os devaneios a que Norbert se entrega a princípio vão se tornando progressivamente mais complexos. Ele cria para "Gradiva" uma identidade, uma origem e um momento histórico em que teria vivido. Cria todo um enredo que contextualiza o movimento da escultura, e segundo o qual "Gradiva", uma jovem 
pompeana, estava a caminho de um templo quando o Vesúvio entrou em erupção e a soterrou junto com o resto da população da cidade em 79 d.C. Freud (1907) observa que "Pouco a pouco Norbert Hanold colocou todo o seu acervo de conhecimentos arqueológicos a serviço desta e de outras fantasias relativas ao modelo da escultura." A escultura se corporifica num ser real para ele, tão real que o motiva a ir à Itália procurá-la, ainda que ele não soubesse a princípio que esta era a razão de sua viagem.

Os devaneios vão assumindo as proporções de um delírio, à medida que ele vai agregando ao seu enredo sobre a "Gradiva" elementos da realidade. Assim, ao invés de a realidade servir como freio às fantasias criadas por Norbert (por exemplo, a lagartixa que foge à presença de Zoe - uma mulher de carne e osso - e o próprio fato de ela falar alemão), seus dados são incorporados às suas criações, realimentando, assim, aquilo que Freud já chama de seu delírio.

Freud (1907), ao se deter na questão de saber se a fantasia de Norbert teria ou não ocorrido independentemente de sua vontade, conclui que se trata realmente de um delírio, conforme foi acima mencionado, e argumenta:

O autor refere-se com frequiência ao estado de Norbert Hanold como "delírio", e não temos motivos para refutar essa designação. Podemos apontar duas características principais de um "delírio" que, se não o descrevem de forma exaustiva, o distinguem de outras perturbações. Em primeiro lugar, o delírio pertence ao grupo de estados patológicos que não produzem efeito direto sobre o corpo, mas que se manifestam apenas por indicações mentais. Em segundo lugar, é caracterizado pelo fato de que nele as "fantasias" ganharam a primazia, transformando-se em crença e passando a influenciar as ações.

Os devaneios de Norbert com relação à "Gradiva" tornaram-se um delírio, cujo sentido é identificado por Freud como o amor do jovem por Zoe, que foi recalcado e o qual ele lutava para manter neste estado. Por isso Norbert não podia, ao longo de seus encontros com a "Gradiva", lembrar-se de que ela era Zoe, e de sua amizade infantil com ela. Segundo Sklar (1989: 69), ele

... parecia resistir ao seu ressurgimento, o que leva Freud a concluir que ali houvera o "recalque" de um "traço mnêmico" (Erinnerungspur). Este recalcamento não implicou a extinção da ação da lembrança, sendo isto explicado na teoria psicanalítica pela seguinte lei: o recalcado persiste, retornando modificado muito tempo depois do ocorrido. O desenvolvimento da fantasia de Norbert pode ser entendido como uma ramificação do seu recalcado amor pela jovem.

Freud fez a análise de uma fantasia que apresentava um jogo entre as diferentes percepções do protagonista, as diferentes situações a que se viu submetido e os elementos concretos que renovaram em cada situação as suas percepções (Sklar, 1989). Ele demonstra que o curso do tratamento deve seguir o espaço da própria 


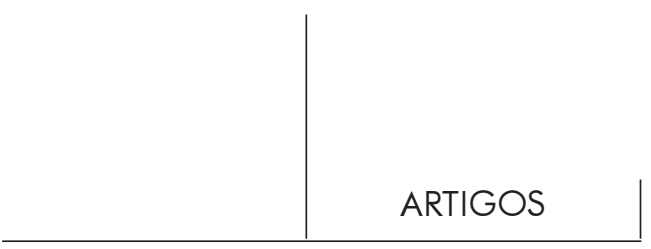

construção delirante, através do qual ocorreria a cura. É o que de fato se dá ao final da obra, quando Norbert acaba por encontrar, com a ajuda de Zoe, o sentido e significado de toda a sua construção fantasiosa - que se encontravam armazenados entre suas antigas e "esquecidas" lembranças infantis.

\section{Conclusão}

O objetivo deste trabalho foi desenvolver um estudo de fundamentação psicanalítica sobre os conceitos de delírio, fantasia e devaneio, com vistas a compreender um pouco melhor a natureza e funcionamento de cada um desses conceitos e tornar um pouco mais claras as aproximações e diferenças entre eles, de forma a evitar possíveis confusões e deturpações teóricas, tanto na compreensão de quadros neuróticos quanto psicóticos.

Este estudo possibilitou uma série de levantamentos e reflexões a respeito de cada tema, e também a evidenciação de alguns pontos de freqüentes dificuldades e confusões, decorrentes de uma certa indistinção teórica no que concerne às "delimitações de território" entre alguns conceitos. Tais confusões são, por sua vez, suscetíveis de produzir diversos mal-entendidos, como, por exemplo, os citados por Naguera (1969), quanto ao lugar dos devaneios dentro da gama de produções mentais conscientes e inconscientes que genericamente se chama "fantasia", e à maneira segundo a qual identificar as nuances que determinam os devaneios em relação aos diversos outros níveis de fantasia; ou ainda, a título de exemplo, como se viu na discussão do capítulo anterior sobre o caso "Gradiva", os devaneios ou divagações da personagem Norbert, que parecem progressivamente dominá-lo até atingir as proporções de um delírio. Estas questões, além das dúvidas que levantam por si próprias, abrem também uma outra discussão, mais genérica, referente a saber se é possível falar de um continuum dentro do qual os conceitos discutidos neste trabalho (delírio, fantasia e devaneio) poderiam ser diferenciados a partir de um critério de intensidade, ou seja, do espaço que ocupam no cenário mental em concorrência com os elementos da realidade (pois neste caso teriam a mesma base estrutural), ou se estes conceitos seriam de fato entidades estruturalmente diferentes, apesar de possuírem ligações ou influências entre si.

Apesar das diferentes posições que esta questão de fato parece suscitar, uma vez que tanto nas considerações correntes quanto na literatura psicanalítica encontram-se momentos em que as passagens de uma situação (por exemplo, de devaneio) para outra (de delírio) são tratadas como resultado de uma intensificação de sintoma - como se pode observar na colocação de Freud (1907) de que os devaneios desenfreados de Norbert realmente se tornaram um delírio ${ }^{6}$ - a psicanálise

6. Vide seção anterior. 


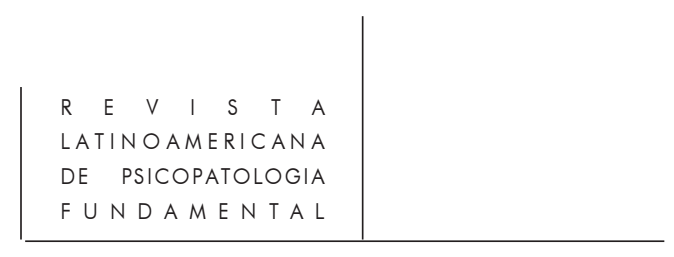

considera que delírio, fantasia e devaneio são conceitos que apresentam diferenças importantes entre si, e que, portanto, precisam ser claramente estabelecidas. A partir deste estudo, pode-se compreender que a "fantasia" é um fenômeno presente nas bases do desenvolvimento humano, intrinsecamente ligado às primeiras experiências sexuais infantis e à problemática do desejo; faz parte da constituição psíquica de um sujeito, e permeia toda a sua vida mental, em seus diversos níveis. Pode-se, portanto, encontrar elementos provenientes da esfera das produções fantasiosas tanto num discreto devaneio neurótico, do qual o indivíduo tem total consciência e controle, quanto num delírio psicótico, aparentemente desprovido de qualquer sentido, lógica ou vínculo com a realidade. Neste sentido, é correto considerar as pontes e relações possíveis entre os fenômenos de delírio, fantasia e devaneio. De fato, eles têm pontos de aproximação entre si, como a constatação feita pela psicanálise de que os três possuem, por exemplo, a função de realização de desejos. Há, entretanto, características que os separam radicalmente, e que devem ser levadas em consideração.

No sentido da diferenciação conceitual, pode-se dizer, de forma sucinta, que os processos, mecanismos envolvidos, e mesmo funções de cada um dos fenômenos aqui considerados não devem ser confundidos. Apesar de se considerar, por exemplo, que tanto delírio, quanto fantasia e devaneio possuem a função semelhante de realização de desejos, deve-se sempre ter em mente as diferenças categóricas impostas pela questão do contato ou não com a realidade, da tentativa ou não de sua substituição pelas produções imaginativas, do caráter ou não de tentativa de cura (no caso de uma psicose) e do lugar, de maneira geral, que tais produções ocupam dentro da dinâmica psíquica do sujeito.

O fato de as fantasias estarem por trás dos acontecimentos mentais de forma geral contribui para a indistinção conceitual que causa tanta controvérsia no uso corrente de termos como Phantasie, conforme colocado por Laplanche \& Pontalis (1986) e discutido ao longo deste trabalho. Assim, utiliza-se "fantasias" para referirse a "devaneios", e muitas vezes "delírios" neuróticos (como no caso do Homem dos ratos) passam apenas por "fantasias", por não se enquadrarem num quadro psicótico.

Não se pretende aqui propor uma "guerra" contra o uso descomprometido dos termos referidos. No cotidiano, todos eles são amplamente utilizados pelo senso comum, sem que seu uso cause maiores complicações ou danos à compreensão. Entretanto, no meio científico, o mesmo descompromisso pode provocar, como provoca, sérios mal-entendidos conceituais. Neste sentido, é importante se ter claro as semelhanças e diferenças entre cada fenômeno e a importância do uso criterioso de seus conceitos, como condição para o progresso da pesquisa em psicanálise e para que se venha a diminuir, progressivamente, as lacunas conceituais existentes. 


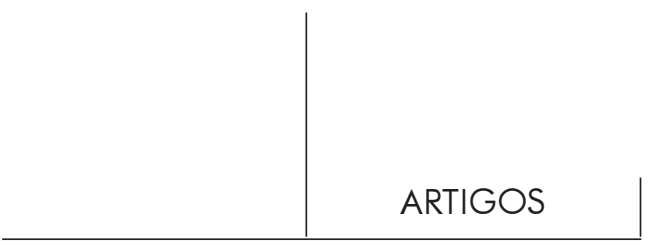

Referências bibliográficas

Aulagnier, P. O sentido perdido (Ou o esquizo e a significação). In Katz, Chaim S. Psicose - uma leitura psicanalítica. São Paulo: Escuta, 1991.

De Waelhens, A. A interpretação psicanalítica da psicose. A metáfora paterna e a foraclusão. In As psicoses - ensaio de interpretação analítica e existencial. Rio de Janeiro: Jorge Zahar, 1990.

Freud, S. (1897). Carta 75. In Extratos dos documentos dirigidos a Fliess. E.S.B. Rio de Janeiro: Imago, 1950. v. I.

(1907). Escritores criativos e devaneios. E.S.B. Rio de Janeiro: Imago, 1976. v. IX

(1907). Delírios e sonhos na "Gradiva" de Jensen. Op. cit. v. IX.

(1909). Notas sobre um caso de neurose obsessiva. Op. cit. v. X.

(1911). Notas psicanalíticas sobre um relato autobiográfico de um caso de paranóia

(Dementia Paranoides). Op. cit. v. XII.

(1914). Sobre o narcisismo: uma introdução. Op. cit. v. XIV.

(1915). Os instintos e suas vicissitudes. Op. cit. v. XIV.

(1919). Uma criança é espancada - Uma contribuição ao estudo da origem das

perversões sexuais. Op. cit. v. XVII.

. (1920). Além do princípio do prazer. Op. cit. v. XVIII.

. (1924). Neurose e psicose. Op. cit. v. XIX.

Laplanche, J. \& Pontalis, J.-B. Vocabulário da psicanálise. 9a ed. São Paulo: Martins Fontes, 1986.

Mezan, R. Freud: a trama dos conceitos. São Paulo: Perspectiva, 1982.

NAGuera, H. Fantasias oníricas. In Conceitos psicanalíticos básicos da teoria dos sonhos. São Paulo: Cultrix, 1969. v. II.

SAfouan, M. Da foraclusão. In KATz, Chaim S. Psicose - uma leitura psicanalítica. São Paulo: Escuta, 1991.

Sklar, S. A teoria freudiana e Três escritos de Freud sobre a arte. In $O$ espaço imanente - um estudo psicanalítico sobre a arte em Sigmund Freud e Jacques Lacan. Rio de Janeiro: Imago, 1989.

\section{Resumos}

Trabajo teórico de énfasis psicoanalítico con el propósito de estudiar los fenómenos delirio, fantasía y devaneo, para entender sus naturalezas y procesos, mecanismos y tareas dentro de la dinámica psíquica humana. Se utilizan como referencia los casos "El hombre de las ratas", el "Caso Schreber" y "La Gradiva” de Jensen, así como también el artículo de Freud "un niño es golpeado", para ilustrar las reflexiones. Las conclusiones indican que los tres conceptos son estructuralmente diferentes, con procesos, mecanismo y tareas propias, pero con acercamientos similares que podrían conducir al malentendido.

Palabras llave: Delirio, fantasía, devaneo, neurosis, psicosis 
Travail theorique d'intérêt psychanalytique dont le but est d'étudier les phénomènes de délire, fantaisie et rêverie à fin de comprendre leur nature et processus, leurs mécanismes et leurs rôles dans la dynamique psychique humaine. Les cas de "Homme aux Rats", "Le cas Schreber" et "Gradiva" de Jensen sont utilisés comme référence, de même que l'article de Freud "Un enfant est battu", pour illustrer les réflexions. La conclusion nous indique que ce sont trois concepts structurellement differents, avec des processus, mécanismes et rôles propres, mais avec des rapprochements qui pourraient prêter à confusion.

Mots clés: Délire, fantaisie, rêverie, névrose, psychose

Theoretical work of psychoanalytic interest with the purpose of studying the phenomena of delusion, fantasy and reverie, in order to understand their nature and processes, their mechanisms and tasks within psychic human dynamics. The cases "Homem dos ratos" (Rats' man), the "Schreber Case" and "Gradiva" of Jensen are used as reference, as well as Freud's paper "A child is beaten", to illustrate the reflections. The conclusions indicate that the three concepts are structurally different, with own processes, mechanism and tasks, but with similar approaches that could lead to misunderstanding.

Key words: Delusion, fantasy, reverie, neurosis, psychosis

Versão inicial recebida em dezembro de 2000

Versão revisada recebida em agosto de 2001 